\title{
Comparison of near miss obstetric events and maternal deaths in a tertiary care teaching hospital from Eastern India
}

\author{
Sushree Samiksha Naik*, Subhra Ghosh
}

Department of Obstetrics and Gynecology, Srirama Chandra Bhanja Medical College and Hospital, Cuttack, Odisha, India

Received: 17 June 2018

Accepted: 24 July 2018

*Correspondence:

Dr. Sushree Samiksha Naik,

E-mail:dr.sushree@yahoo.com

Copyright: (c) the author(s), publisher and licensee Medip Academy. This is an open-access article distributed under the terms of the Creative Commons Attribution Non-Commercial License, which permits unrestricted non-commercial use, distribution, and reproduction in any medium, provided the original work is properly cited.

\begin{abstract}
Background: Obstetrics near miss is an important indicator that reflects the quality of obstetrics care in a health facility. Timely audit of the obstetrics near miss data would help in reducing maternal mortality.

Methods: A retrospective chart review of the maternal near miss (MNM) and death based on WHO 2009 criteria was carried out in a tertiary care teaching hospital from Eastern India over 12 months. Main outcome measures were severe acute maternal morbidity (MNM) and maternal deaths.

Results: During the study period, there were 9204 deliveries, 116 near miss cases, and 69 maternal deaths. The MNM incidence ratio was $13.75 / 1000$ live births, MNM to mortality ratio was $1.68: 1$, and mortality index was $37.3 \%$. A total of 126 cases were referred, while 5 cases were booked at our hospital. Hypertensive disorders accounted for the highest number of near miss cases $(40.5 \%)$, followed by sepsis (31\%), haemorrhage (18\%), and dystocia (10\%). The mortality index was $36.58 \%, 33.33 \%, 19.23 \%$, and $07.6 \%$ for hypertensive disorders, sepsis, haemorrhage, and dystocia, respectively. Most common causes of maternal deaths were hypertensive disorders, followed by systemic infections, HELLP syndrome, embolism, haemorrhage, malaria, and ruptured uterus. On bivariate analysis, there was an increased risk of maternal death in those illiterate, incomplete antenatal check-up $(<3)$, multipara, preterm pregnancy, and home delivery.

Conclusions: Hemorrhage and hypertensive disorders are the leading causes of MNM events and mortality. Early identification, remedial measures, and timely treatment would help to decrease the burden of maternal near miss and mortality.
\end{abstract}

Keywords: Hypertensive disorders, Pregnancy, Maternal mortality, Obstetric near miss, Obstetric hemorrhage

\section{INTRODUCTION}

India has made significant progress in reducing its maternal mortality rate (MMR) from 167 (sample registration system [SRS], 2011-13) to 130 (SRS, 201416) per thousand live births (LB); however, there is a long way to go on this journey to meet the millennium development goals. ${ }^{1}$ The quality of obstetrics care and health status of pregnant women is not reflected by mortality indicators alone. The recent concept is maternal near miss (MNM) or severe acute maternal morbidity
(SAMM) that describes an event in which a pregnant woman comes close to maternal death but does not die - a "near miss".,3 This concept is superior over maternal death in drawing attention to surviving women's reproductive health and lives and is equally applicable in developing as well as developed nations. The basic difference between MNM and maternal death is that a woman follows almost same pathways in both the conditions but does not dies in MNM as a result she can be interviewed directly about the condition and more data can be generated that can prevent MNM and indirectly 
the mortality also. ${ }^{4,5}$ In many developed nations, maternal mortality has fallen to single digits but not the near miss events, making them more useful to evaluate the available health system. ${ }^{6}$

After the development of MNM concept and till 2009, the same was not used properly due to the lack of uniformity in the criteria adopted. In 2009, World Health Organization (WHO) came up with clinical, laboratory, and management criteria for the identification of these cases. ${ }^{6}$ In this criterion WHO defined a maternal near miss case as "a woman who nearly died but survived a complication that occurred during pregnancy, child birth or within 42 days of termination of pregnancy". In 2011, WHO elaborated the criteria for MNM. $^{7}$ The WHO inclusion criteria for a maternal near miss are categorized in three areas: clinical criteria, laboratory-based criteria and management-based criteria. The goal is that these identification criteria may be used in any setting, regardless of the development status. The criteria are unique in that it incorporates both Mantel's and Waterston's criteria. ${ }^{8,9}$ So if one of the criteria fails to pick the case, the other makes it up, thus minimizing the chance of missing the case.

\section{METHODS}

\section{Settings}

This retrospective study was conducted in the Obstetrics and Gynecology department of a tertiary care teaching hospital in Eastern India over 12 months period. Medical files of pregnant women and those who delivered were retrieved. The study was approved by the Hospital Ethics Committee.

\section{Participants}

\section{Inclusion criteria}

- Maternal near-miss cases were defined as women with at least one near-miss event as follows: acute obstetric complication that immediately threaten a woman's survival but do not result in her death, either by chance or because of hospital care she receives during pregnancy labor or within 6 weeks after termination of pregnancy or delivery. ${ }^{6}$

- For these events, the following disease-specific criteria that were employed by were applied: (I) hemorrhage leading to shock; emergency hysterectomy; coagulation defects and/or blood transfusion of $\geq 2$ litrers; (II) hypertensive disorders in pregnancy including both eclampsia and severe pre-eclampsia with clinical/laboratory indications for termination of pregnancy to save the woman's life; (III) dystocia; uterine rupture and impending rupture, e.g., prolonged obstructed labor with previous caesarean section; and (IV) infection with hyperthermia or hypothermia or a clear source of infection and clinical signs of septic shock.

\section{Exclusion criteria}

- Women who developed the above conditions unrelated to pregnancy (not during pregnancy or 42 days after termination of pregnancy) were not eligible.

A random selection of pregnant women admitted to delivery room was made that served as control.

\section{Data collection and analysis}

For each obstetric condition, the following near miss indices were calculated.

1. MNM incidence ratio refers to the number of maternal near miss cases per 1,000 live births.

2. Maternal near miss: mortality ratio: Proportion between maternal near miss cases and maternal deaths. Higher ratio indicates better care.

3. Mortality index: Number of maternal deaths divided by the number of women with life threatening conditions, expressed as a percentage. The higher the index is more women with the life-threatening condition die (low quality of care), while low index suggests better quality of health care.

For each case, information on socio-demographic characteristics, parity, gestational age at the time of the near-miss morbidity, nature of the obstetric complication(s), presence of organ and/or system dysfunction, duration of hospital stays, and source of referral were collected. Socio-demographic data, parity, and gestational age were compared between the near miss cases and maternal deaths. Same data was collected for control group.

\section{Statistical analysis}

Data were entered in a computer database using SPSS (SPSS Inc., Chicago, IL, USA, version 16.0) for Windows and were double-checked before analysis. The Student's t-test and Chi-square $\left(x^{2}\right)$ test were used to compare means and proportions, respectively. A p-value of $<0.05$ was taken as significant.

\section{RESULTS}

During the study period, there were 9204 deliveries, 8436 live births. Among 152 women suspected of near-miss, 116 were confirmed based on WHO management criteria.

Other 36 were excluded from the analysis, 23 patients left against medical advice (LAMA), and 13 of them showed clinical improvement, not meeting the criterion of them exclusively. An equal number of control was randomly selected from the delivery room data.

Total number of maternal deaths was 69. Maternal near miss ratio was 13.75 per 1000 live-births. Maternal 
mortality ratio was 818 per $1,00,000$ live-births. The total mortality index was $37.3 \%$. Incidence of maternal near miss was $1.4 \%$. Table 1 outlines the near miss events during the study period. Hypertensive disorders accounted for the highest number of near miss cases $(40.5 \%)$, followed by sepsis $(31 \%)$, hemorrhage $(18 \%)$, and dystocia (10\%).

Table 1: Identified near miss events during the study period.

\begin{tabular}{|lll|}
\hline Near miss event & Number $(\%)$ & $\begin{array}{l}\text { Percentage } \\
(\%) \text { of total }\end{array}$ \\
\hline Hypertensive disorders & $47(40.5)$ & $40.51 \%$ \\
\hline Severe pre-eclampsia & 35 & $30.17 \%$ \\
\hline Eclampsia & 12 & $10.34 \%$ \\
\hline Hemorrhage & $21(18.1)$ & $18.10 \%$ \\
\hline Ectopic & 3 & $02.58 \%$ \\
\hline Abortion & 3 & $02.58 \%$ \\
\hline Placenta praevia & 4 & $03.44 \%$ \\
\hline Abruptio placentae & 1 & $0.86 \%$ \\
\hline Hydatidiform mole & 1 & $0.86 \%$ \\
\hline $\begin{array}{l}\text { Post-partum } \\
\text { hemorrhage }\end{array}$ & 9 & $7.7 \%$ \\
\hline Infection/sepsis & $36(31)$ & $31.03 \%$ \\
\hline Dystocia & $12(10.3)$ & $10.34 \%$ \\
\hline Impending rupture & 3 & $02.58 \%$ \\
\hline Ruptured uterus & 9 & $07.76 \%$ \\
\hline Total & 116 & $100.00 \%$ \\
\hline
\end{tabular}

The mortality index was $36.58 \%, 33.33 \%, 19.23 \%$, and $07.6 \%$ for hypertensive disorders, sepsis, hemorrhage, and dystocia, respectively. Maternal death also studied during the study period, and the causes included: hypertensive disorders $(39.1 \%)$, systemic infections (26.1\%), HELLP syndrome (6\%), embolism (4.3\%), hemorrhage $(4.3 \%)$, malaria $(2.6 \%)$, uncertain $(2.6 \%)$ and ruptured uterus $(1 \%)$.

The mortality index was calculated for each event was as follows: is highest for hypertensive disorders (36.6\%), followed by systemic infections (33.3\%), hemorrhage (19.2\%), and dystocia (7.7\%).

In both the maternal near miss and maternal death groups, ages of the women ranged from 18 to 43 years, and most were in the age group of 20 to 30 years. Among the 116 near miss cases, the mean age of admission was $26 \mathrm{yrs}$, minimum at 18 years and maximum at 43 years.

Around $81 \%$ patients were from rural area and $19 \%$ from urban area. On bivariate analysis, there was an increased risk of maternal death in those illiterate, incomplete antenatal check-up $(<3)$, multipara, preterm pregnancy, and home delivery as shown in Table 2 .

Factors like booking of pregnancy, poor socio-economic status, self-mode of transport to hospital, mode of delivery (vaginal vs. caesarean), fetal outcome (live born or IUD) did not significantly affected the maternal outcome. Antenatal complications have been outlines in maternal near miss and maternal death cases in Table 3 .

Table 2: Bivariate analysis of factors affecting maternal death.

\begin{tabular}{|c|c|c|c|}
\hline $\begin{array}{l}\text { Background } \\
\text { factor }\end{array}$ & $\begin{array}{l}\text { Maternal } \\
\text { death }(n=69)\end{array}$ & $\begin{array}{l}\text { OR }(95 \% \\
\text { CI) }\end{array}$ & $\begin{array}{l}\text { P- } \\
\text { value }\end{array}$ \\
\hline \multicolumn{4}{|l|}{ Education } \\
\hline Illiterate & $28(40.6)$ & $\begin{array}{l}2.62 \\
(1.36-5.05)\end{array}$ & 0.003 \\
\hline Literate* & - & 1 & \\
\hline \multicolumn{4}{|c|}{ Pregnancy booked } \\
\hline No & $64(92.8 \%)$ & $\begin{array}{l}1.48 \\
(0.5-4.39)\end{array}$ & \\
\hline Yes & - & 1 & 0.48 \\
\hline \multicolumn{4}{|c|}{ Poor socio-economic status } \\
\hline Yes & $54(78.3 \%)$ & $\begin{array}{l}1.37 \\
(0.68-2.77)\end{array}$ & 0.37 \\
\hline No & - & 1 & \\
\hline \multicolumn{4}{|c|}{ Incomplete ANC (<3) } \\
\hline Yes & $61(88.4 \%)$ & $\begin{array}{l}3.86 \\
(1.68-8.87)\end{array}$ & 0.001 \\
\hline No & - & 1 & \\
\hline \multicolumn{4}{|c|}{ Mode of transport } \\
\hline Self & $46(66.7 \%)$ & $\begin{array}{l}1.14 \\
(0.61-2.13)\end{array}$ & 0.69 \\
\hline Ambulance & - & 1 & \\
\hline \multicolumn{4}{|l|}{ Referral } \\
\hline Self & $\begin{array}{c}13 \\
(18.85 \%)\end{array}$ & $\begin{array}{l}1.84 \\
(0.80-4.24)\end{array}$ & 0.15 \\
\hline $\begin{array}{l}\text { From a } \\
\text { health } \\
\text { facility }\end{array}$ & - & 1 & \\
\hline \multicolumn{4}{|l|}{ Parity } \\
\hline Multi & $53(76.8 \%)$ & $\begin{array}{l}2.26 \\
(1.15-4.41)\end{array}$ & 0.016 \\
\hline Primi & - & 1 & \\
\hline \multicolumn{4}{|c|}{ Duration of pregnancy } \\
\hline$<37$ weeks & $36(52.2 \%)$ & $\begin{array}{l}6.92 \\
(3.23-14.84)\end{array}$ & 0.001 \\
\hline$\geq 37$ weeks & - & 1 & \\
\hline \multicolumn{4}{|c|}{ Place of delivery } \\
\hline Hospital & $16(24.2 \%)$ & $\begin{array}{l}0.28 \\
(0.12-0.65)\end{array}$ & 0.002 \\
\hline Home & - & 1 & \\
\hline \multicolumn{4}{|c|}{ Mode of delivery } \\
\hline VD & $33(62.3 \%)$ & $\begin{array}{l}1.87 \\
(0.91-3.82)\end{array}$ & 0.08 \\
\hline LSCS & - & 1 & \\
\hline \multicolumn{4}{|c|}{ Outcome of delivery } \\
\hline Live born & $29(54.7 \%)$ & $\begin{array}{l}1.66 \\
(0.84-3.27)\end{array}$ & 0.14 \\
\hline IUD & - & 1 & \\
\hline
\end{tabular}

*Literate (patients having primary education, high school and college) 
Table 3: Antenatal complications in maternal near miss and maternal death cases.

\begin{tabular}{|c|c|c|c|c|}
\hline Complications & $\begin{array}{l}\text { Maternal } \\
\text { near miss } \\
(\mathrm{N}=116)\end{array}$ & $\%$ & $\begin{array}{l}\text { Maternal } \\
\text { death } \\
(\mathrm{N}=69)\end{array}$ & $\%$ \\
\hline Pre-eclampsia & 46 & 39.67 & 11 & 15.94 \\
\hline Jaundice & 16 & 13.79 & 13 & 18.84 \\
\hline $\begin{array}{l}\mathrm{H} / \mathrm{o} \\
\text { convulsion }\end{array}$ & 11 & 09.48 & 19 & 27.53 \\
\hline MODS & 36 & 31.03 & 17 & 24.63 \\
\hline $\begin{array}{l}\text { No } \\
\text { complications }\end{array}$ & 7 & 06.03 & 9 & 12.06 \\
\hline
\end{tabular}

Table 4: Post-natal obstetric complications in maternal near miss and maternal death cases.

\begin{tabular}{|lllll|}
\hline & $\begin{array}{l}\text { Maternal } \\
\text { near } \\
\text { miss } \\
(\mathrm{N}=116)\end{array}$ & $\%$ & $\begin{array}{l}\text { Maternal } \\
\text { death } \\
(\mathrm{N}=69)\end{array}$ & $\%$ \\
\hline PPH & 27 & 23.24 & 14 & 20.22 \\
\hline ARF & 15 & 12.93 & 5 & 7.24 \\
\hline $\begin{array}{l}\text { Ruptured } \\
\text { uterus }\end{array}$ & 12 & 10.37 & 3 & 4.34 \\
\hline HELLP/DIC & 8 & 6.89 & 7 & 10.14 \\
\hline Shock & 40 & 34.48 & 22 & 31.88 \\
\hline Sepsis/MODS & 14 & 12.09 & 18 & 26.18 \\
\hline
\end{tabular}

Post-natal obstetric complications in maternal near miss and maternal death cases have been outlined in Table 4. Interventions done to save lives in maternal near miss and maternal death cases have been outlined in Table 5 .

Table 4: Interventions done to save lives in maternal near miss and maternal death cases.

\begin{tabular}{|lllll|}
\hline Interventions & $\begin{array}{l}\text { Maternal } \\
\text { near } \\
\text { miss } \\
(\mathrm{N}=116)\end{array}$ & $\%$ & $\begin{array}{l}\text { Maternal } \\
\text { death } \\
(\mathrm{N}=\mathbf{6 9})\end{array}$ & $\%$ \\
\hline $\begin{array}{l}\text { Hemodynamic } \\
\text { Support }\end{array}$ & 78 & 67.24 & 61 & 88.40 \\
\hline $\begin{array}{l}\text { ICU care } \\
\text { Emergency } \\
\text { hysterectomy }\end{array}$ & 62 & 53.44 & 16 & 13.79 \\
\hline Hemodialysis & 14 & 17.24 & 1 & 1.44 \\
\hline
\end{tabular}

Duration of hospital stay was as follows: in maternal near miss cases, 13 cases (11.2\%) admitted up to 7 days and 103 cases $(88.8 \%)$ admitted $>7$ days. The duration of hospital stays ranged from 5 to 32 days with a mean stay of 13.95 days in the near miss group.

In the maternal death group, duration of stay ranged from 45 minutes to 16 days with a mean stay of 5 days. Most of the deaths occurred in first 12 hours of admission indicating severity of the conditions of the patients.

\section{DISCUSSION}

The present study was conducted in the Eastern part of India, and the results of maternal near-miss and its mortality index reflect the quality of care provided by a health facility. The maternal near-miss ratio in the present study (13.73 per 1,000 live births) is within the wide range of ratios reported in studies from other developing countries which used similar criteria for near-miss definition (12.3 to 82.3 per 1,000 deliveries). ${ }^{10,11}$ It might not be appropriate to compare our results with results in the industrialized/developed countries because of different selection criteria for near-miss cases. The reduction of the present high rates of near-miss cases may be achieved by improving the resources for managing severe morbidities e.g. easy access to better health facility with provision of intensive care units (ICUs). ${ }^{12,13}$ The present study was conducted in a tertiary care teaching hospital where the cases were managed in specialized high-risk ward which is close to the labour room and operating theatre (OT). Generally, $<10 \%$ of near-miss cases in low resource settings receive high level or ICU care. ${ }^{14-18}$ Furthermore, the criteria for admission to the ICUs are variable and depend on the availability and capacity of the ICU and on the institutional guidelines for ICU admission.

In an updated systematic review on severe maternal morbidity and maternal near miss, the authors included new articles published between 2004 and 2010. ${ }^{19}$ A total of 82 studies from 46 countries were included in this review. Studies were mainly retrospective, crosssectional and except for one study in Brazil, all of the studies used data from facilities, mainly tertiary-care hospitals. Except for the studies reporting on emergency hysterectomies and intensive-care unit (ICU) admissions, a majority of the studies defined near miss as a woman who almost died but survived through chance or as a result of good care received. Overall, there were three major approaches to the identification: (a) diseasespecific criteria (i.e. severe preeclampsia, severe postpartum hemorrhage), (b) management-based criteria (i.e. admission to ICU, need for a blood transfusion), or (c) organ system dysfunction-based criteria. The majority used management-based criteria (33 studies used emergency hysterectomies, and 18 used ICU admissions to define near miss). Seven studies used disease-specific criteria, nine used organ system dysfunction criteria, and 14 used a combination of disease, organ and management-based criteria. Study-specific near miss rates differed based on the method of identification and region. Studies using disease-specific criteria reported a higher percentage of near-miss cases, and a wider range of estimates compared with the other criteria, 0.6 to $14.98 \%$. Near-miss rates identified by managementspecific criteria ranged between 0.04 and $4.54 \%$. However, it should be noted that within this group, studies identifying emergency hysterectomies reported lower percentages $(0.04-0.26 \%)$ than studies using ICU admissions $(0.04-4.54 \%)$. Organ dysfunction-based 
criteria reported the near-miss rate ranging between 0.14 and $2.3 \%$. Eight of nine studies used either "Mantel or modified Mantel criteria" in this category and reported rates between 0.14 and $0.92 \%$. These criteria were first introduced in South Africa and combine organ dysfunction and certain management markers such as intensive-care admission, emergency hysterectomy to identify near-miss cases. This criterion is arguably the most stable compared with others in this review. Based on their income, all African and Asian countries (where there were near-miss studies) except Saudi Arabia and Kuwait are considered low-income or middle-income countries. The upper near-miss rate ranged from $4.93 \%$ in Latin America and the Caribbean, through 5.07\% in Asia to $14.98 \%$ in Africa (excluding outliers). In contrast, studies from high-income countries (Europe, North America and Australia) reported an upper near-miss rate from a low of $0.79 \%$ in Europe to a high of $1.38 \%$ in North America: the lowest rates across all the criteria compared with those from low-income and middleincome countries. Depending on the resources of a facility or a country overall, the criteria used for identification of near misses vary. For example, in highincome countries where facility deliveries are systematic, national level data are the norm; more sensitive markers have been used to identify the near-miss cases, whereas in resource-poor settings, management-based criteria are more commonly used. In low and middle-income countries, approximately $1 \%$ of the women experienced a near-miss event before, during or after delivery as identified by organ dysfunction criteria. It was around $0.25 \%$ in higher-income countries. Management- specific criteria using ICU admissions and emergency hysterectomies were under $1 \%$ across all regions, except the two studies from the LAC region. Using mixed criteria combining different markers, the rate ranges between 2.10 and $4.43 \%$ in low-income and middleincome countries and 0.09 and $1.38 \%$ in higher-income countries.

The authors of the review could able to conduct metaanalysis of 11 studies for Mantel criteria and 40 studies for emergency hysterectomy. For the Mantel-based criteria, the estimate of near miss was $0.42 \%$ (95\% CI $0.40-0.44 \%$ ). For the emergency hysterectomy criteria, the near-miss rate was $0.039 \%$ (95\% CI $0.037-0.42 \%$ ). Despite the very narrow range of the confidence intervals, the I-squared was high: $98.3 \%$ for the Mantelbased criteria and $95.5 \%$ from the emergency hysterectomy criteria, suggesting significant heterogeneity between studies.

In another recent systematic review of maternal near miss and mortality due to postpartum hemorrhage (PPH) including 26 studies published from 1995 to 2014, the median near-miss ratio for PPH was 3 per 1000 live births. $^{20}$ The mortality index for $\mathrm{PPH}$ was $6.6 \%$ (range $0.0 \%-40.7 \%$ ). The mortality index was highest in lowincome countries and lower middle-income countries. Overall, PPH was the most frequent contributor to obstetric hemorrhage, with atonic uterus identified as the main cause.

In the present study, there was a very high total mortality index for near-miss cases $(68.1 \%)$, which mean that for every two maternal death there are three near miss-cases. This reflects a poor care and unacceptable high maternal mortality in this setting. Hypertensive disorders and septicemia were the major causes of maternal death and morbidity in the present study. This signifies a poor response of the system to modify these obstetric complications or perhaps substandard care where no audit has been performed. Most (90\%) of the cases were referred from rural hospitals, which are managed by medical officers who are not well trained in emergency obstetric care. Therefore, training of these providers as well as system management in all its levels might improve and ultimately change these results. In this setting, the health care providers were faced with a high percentage of life-threatening obstetric situations.

Complications resulted in near-miss and maternal deaths with septicemia and hypertensive disorders with a higher mortality index, which constitute an important and significant threat to the survival of pregnant women. The mortality indices for dystocia (7.6\%) and hemorrhage $(19.23 \%)$ were least of all the events. This could be due to the 24 hours availability of blood bank services and the emergency hysterectomy services. An increased level of care and effort are required to deal with near-miss events with a high mortality index (e.g., infection, hypertensive disorders). The delay in referral was a major cause of maternal morbidity and mortality in the present study. Establishment of a tertiary care in each district or upgradation of the district hospital infrastructure with availability of ICUs and well-trained obstetricians is essential to address these problems to certain extent.

\section{CONCLUSION}

There is a high frequency of maternal morbidity and mortality at the level of this facility. Therefore, maternal health policy needs to be concerned not only with averting the loss of life, but also with preventing or ameliorating maternal- near miss events (hypertensive disorders, sepsis, hemorrhage, and dystocia) at all care levels including primary level. The delays in referrals are a major cause of morbidity and mortality. Establishment of a tertiary care in each district is essential. Delayed diagnosis, inappropriate transfer, and inadequate utilization of resources might have been the cause for maternal morbidities and mortalities in our study. Along with increased awareness of one's own health, health education may go a long way in improving the quality of obstetric care.

Funding: No funding sources

Conflict of interest: None declared

Ethical approval: The study was approved by the Institutional Ethics Committee 


\section{REFERENCES}

1. Special Bulletin on Maternal Mortality in India 2014-16 Sample Registration System (SRS) office of Registrar General, India, May 2018. Available at http://www.censusindia.gov.in/2011common/Sample_Registration_System.html. Accessed 15th June 2018..

2. Stones W, Lim W, Al-Azzawi F, Kelly M. An investigation of maternal morbidity with identification of life-threatening 'near miss' episodes. Health Trends. 1991;23(1):13-5.

3. Say L, Souza JP, Pattinson RC; WHO working group on Maternal Mortality and Morbidity classifications. Maternal near miss-towards a standard tool for monitoring quality of maternal health care. Best Pract Res Clin Obstet Gynaecol. 2009;23(3):287-96.

4. Souza JP, Gülmezoglu AM, Vogel J, Carroli G, Lumbiganon P, Qureshi Z, et al. Moving beyond essential interventions for reduction of maternal mortality (the WHO Multicounty Survey on Maternal and Newborn Health): a cross-sectional study. Lancet. 2013;381(9879):1747-55.

5. Tallapureddy S, Velagaleti R, Palutla H, Satti CV. "Near-Miss" Obstetric events and maternal mortality in a Tertiary Care Hospital. Indian J Public Health. 2017;61(4):305-8.

6. PS R, Verma S, Rai L, Kumar P, Pai MV, Shetty J. "Near miss" obstetric events and maternal deaths in a tertiary care hospital: an audit. J Pregnancy. 2013;2013.

7. World Health Organisation, Department of Reproductive Health and Research. Evaluating the Quality of Care for Severe Pregnancy Complications: The WHO Near Miss Approach for Maternal Health. Geneva, Switzerland: World Health Organization; 2011. Available http://www.who.int/reproductivehealth/publications/ monitoring/9789241502221/en/. Accessed 15th June 2018.

8. Mantel GD, Buchmann E, Rees H, Pattinson RC. Severe acute maternal morbidity: a pilot study of a definition for a near-miss. Br J Obstet Gynaecol. 1998;105(9):985-90.

9. Waterstone M, Bewley S, Wolfe C. Incidence and predictors of severe obstetric morbidity: case-control study. BMJ 2001;322(7294):1089-93 \&1093-4.

10. Say L, Pattinson RC, Gülmezoglu AM. WHO systematic review of maternal morbidity and mortality: the prevalence of severe acute maternal morbidity (near miss). Reprod Health. 2004;1(1):3.

11. Filippi V, Ronsmans C, Gohou V, Goufodji S, Lardi M, Sahel A, et al. Maternity wards or emergency obstetric rooms? Incidence of nearmiss events in African hospitals. Acta Obstet Gynecol Scand. 2005;84(1):11-6.

12. Murphy CM, Murad K, Deane R, Byrne B, Geary MP, McAuliffe FM. Severe maternal morbidity for 2004-2005 in the three Dublin maternity hospitals. Eur J Obstet Gynecol Reprod Biol. 2009;143(1):347.

13. Baskett TF, Sternadel J. Maternal intensive care and near-miss mortality in obstetrics. BJOG: An Int $\mathbf{J}$ Obstet Gynaecol. 1998 Sep;105(9):981-4.

14. Adisasmita A, Deviany PE, Nandiaty F, Stanton C, Ronsmans C. Obstetric near miss and deaths in public and private hospitals in Indonesia. BMC Preg Childbirth. 2008 Dec;8(1):10.

15. Tallapureddy S, Velagaleti R, Palutla H, Satti CV. "Near-Miss" Obstetric events and maternal mortality in a Tertiary Care Hospital. Indian J Public Health. 2017;61(4):305-308.

16. Km U, Mn D, RS, Datti SN, G K, Laxmi. Effect of a primary postpartum haemorrhage on the "near-miss" morbidity and mortality at a tertiary care hospital in rural bangalore, India. J Clin Diagn Res. 2013;7(6):1114-9.

17. Tunçalp Ö, Hindin MJ, Adu-Bonsaffoh K, Adanu RM. Assessment of maternal near-miss and quality of care in a hospital-based study in Accra, Ghana. Int J Gynaecol Obstet. 2013;123(1):58-63.

18. Adeoye IA, Onayade AA, Fatusi AO. Incidence, determinants and perinatal outcomes of near miss maternal morbidity in Ile-Ife Nigeria: a prospective case control study. BMC Preg Childbirth. 2013;13(1):93.

19. Tuncalp O, Hindin MJ, Souza JP, Chou D, Say L. The prevalence of maternal near miss: a systematic review. BJOG 2012;119(6):653-61.

20. Maswime S, Buchmann E. A systematic review of maternal near miss and mortality due to postpartum hemorrhage. Int J Gynaecol Obstet. 2017;137(1):1-7.

Cite this article as: Naik SS, Ghosh S. Comparison of near miss obstetric events and maternal deaths in a tertiary care teaching hospital from Eastern India. Int J Reprod Contracept Obstet Gynecol 2018;7:361924. 